\title{
a infância de ensinar e aprender: inventando com e como criança a arte de ser professor
}

\author{
mauro britto cunha ${ }^{1}$ \\ prefeitura municipal de são mateus/es, brasil \\ orcid id: https:/ / orcid.org/0000-0001-7905-5669 \\ jair miranda de paiva ${ }^{2}$ \\ universidade federal do espírito santo, brasil \\ orcid id: https:/ / orcid.org/0000-0002-6986-3213
}

\section{resumo}

o artigo busca aproximar o desafio de inventar-se professor (a) ao olhar da infância, dimensão habitada por tempos intensos, cheios de possíveis, conectando esse movimento de invenção aos desafios encontrados no dia a dia do aprender e ensinar nos espaços escolares. Cria a partir desse encontro novas perspectivas e pistas que possam contribuir com o desenvolvimento de olhos capazes de ver, de "desver", de "transver" o mundo, isto é, de vê-lo por ângulos ainda não explorados, novos, inéditos, infantis... Potente o suficiente para dar vida a fazeres educativos que provoquem o (a) professor (a) na complexa arte de construir-se, de inventar-se e, acima de tudo, que preserve a capacidade criadora, própria das "crianças de todas as idades", possibilitando, dessa forma, que o pensar seja experimentado de infinitas e inimagináveis maneiras, enriquecendo e transformando os fazeres e os saberes que habitam o tempo da busca, do vir a ser, do devir-professor, do devir-aprendiz, do devir-escola... Este escrito não busca dar respostas aos desafios e às inquietações apresentadas, mas, sobretudo, pretende ser um exercício cuidadoso de lançar o olhar sobre as questões que afetam diretamente ou indiretamente a caminhada de todos e todas que se aventuram e se desafiam a construir experiências educacionais comprometidas com a transformação e a criação de outras maneiras de relacionar-se com a infância, com as crianças, com a escola, enfim, com a própria invenção de si, como uma arte de percorrer percursos para fazer-se educador, educadora.

palavras-chave: invenção, infância, professor, filosofia

\section{la infancia de enseñar y aprender: inventando con y como niño/a el arte de ser maestra/o}

\section{resumen}

el artículo busca aproximar el desafío de inventarse maestra en la mirada de la infancia, dimensión habitada por tiempos intensos, llenos de posibles, conectando ese movimiento de invención a los desafíos encontrados en el día a día del aprender y enseñar en los espacios escolares. Crea a partir de ese encuentro nuevas perspectivas y pistas que puedan contribuir con el desarrollo de ojos capaces de ver, de "desver", de "transver" el mundo, es decir, de verlo por ángulos aún no explorados, nuevos, inéditos, infantiles... Potente lo suficiente para dar vida a haceres educativos que provoquen a la maestra en el complejo arte de construirse, de inventarse y, por encima de todo, que preserve la capacidad creadora, propia de "niños/as de todas las edades", posibilitando, de esa forma, que el pensar sea experimentado de infinitas e inimaginables maneras, enriqueciendo y transformando los haceres y saberes que habitan el tiempo de la busca, del venir a ser, del devenir maestra, del devenir aprendiz, del devenir escuela... Este texto

\footnotetext{
1 E-mail: maurobrittoc@gmail.com

2 Email: jmipaiva@gmail.com. O coautor agradece à CAPES, PNPD 2017-2018, pela bolsa de pós-doutorado junto ao Nefi-PropEd-UERJ
} 
no busca dar respuestas a los desafíos y a las inquietudes presentadas, sino, sobre todo, pretende ser un ejercicio cuidadoso de lanzar una mirada sobre las cuestiones que afectan directa o indirectamente el camino de todos y todas que se aventuran y se desafian a construir experiencias educativas comprometidas con la transformación y la creación de otras maneras de relacionarse con la infancia, con los niños, con la escuela; en fin, con la propia invención de sí, con el arte de recorrer otros caminos para hacerse educador, educadora.

palabras claves: invención, infancia, maestra, filosofía.

\section{the childhood of teaching and learning: inventing with and as a child the art of being a teacher}

abstract

this article seeks to approach the challenge of inventing oneself as a teacher through the eyes of childhood-a human dimension characterized by intensity, full of possibilities, connecting the movement of invention to the challenges encountered in day-to-day learning and teaching in school spaces. From that encounter with childhood, it is possible to create new perspectives and clues that can contribute to the development of eyes capable of seeing, "unraveling", "overturning" the world--in other words, seeing the world from several angles not yet explored, with new childlike lenses. This approach is potent enough potent to bring to life educational activities that provoke the teacher, in the complex art of building or inventing themselves, and developing the capacity to preserve the creativity of children of all ages. This perspective enables the act of thinking to be experienced in infinite and unimaginable ways, not only enriching but also transforming the practices and knowledge that inhabit the time of searching-the time of becoming teacher, becoming learner, becoming school. This paper does not seek to provide answers to the challenges and concerns presented, but, it is intended to be a careful exercise of looking at the issues that directly or indirectly affect the journey of all who venture out and challenge themselves to build educational experiences committed to the transformation and creation of other ways of relating to childhood, with children, with school, in short, with the very invention of the self, as an art of traversing the paths along which one becomes an educator.

keywords: invention, childhood, teacher, philosophy. 
a infância de ensinar e aprender: inventando com e como criança a arte de ser professor

\section{introdução}

“Eu não queria ocupar o meu tempo usando palavras bichadas de costumes. Eu queria mesmo desver o mundo"

(BARROS, 2010).

Educar não é tarefa simples. Exige-se a capacidade de os educadores e as educadoras estarem em permanente processo de transformação, de (des)construção, de invenções de si.

E o que torna esse desafio ainda mais rico é o fato de vivemos em uma época em que as pessoas, de modo geral, experimentam que o tempo passa depressa, que as relações são condicionadas a movimentos rápidos, aligeirados, em que somos, de certa forma, convencidos a viver sob direções previamente planejadas, organizadas, orientados, sendo quase proibido viver ao sabor dos acontecimentos, dos acasos, dos encontros e (des)encontros não imaginados e previstos.

Com o objetivo de colocarmos cuidadosa atenção nesses movimentos que atravessam cada existência, sugerimos algumas questões para serem pensadas: será que nos tempos que correm, o tempo se faz raridade? Ou é a relação com o tempo que está submetida a uma lógica desinteressante e empobrecida de novidades, carente de novos inícios e possibilidades criadoras? É possível inventar-se professor/professora na perspectiva de outras formas de relação com o tempo, com o outro e consigo mesmo? Será o diálogo com as crianças, com os jovens, com os idosos, com os companheiros de trabalho um elemento revolucionário e transformador na construção e formação dos professores e professoras? Como (re)aprendermos a arte de ver, de "desver", de "transver" nos movimentos que atravessam os espaços de ensino? Há lugar na correria do dia a dia para a vivência de novos acontecimentos? Como podem os infantes colaborar com a invenção de novas maneiras de sermos professor/professora? Que lugar 
terá a infância nesse processo de criação de si? E, por fim, o que terão as crianças para ensinarem àqueles que ensinam?

No presente texto, busca-se de início problematizar a perspectiva da invenção de si, da construção e formação do educador e da educadora, apontando a complexidade do tema e as várias facetas possíveis para lidar com o assunto, inclusive, sugerindo pistas de como, em certa medida, tornar esse fazer interessante e potente.

Em seguida, aprofunda-se o diálogo, no sentido de aproximar o desafio de construir-se docente das contribuições inventivas próprias da infância, do fazer-se infante, objetivando desenvolver olhos capazes de ver, de "desver", de "transver" o mundo, isto é, de vê-lo de um modo novo, inédito, surpreendente, transformador.

Por fim, aventuramo-nos nos tempos intensos e cheios de infinitos, em que a experiência do pensar e o desafio de fazer-se brincam com as descontinuidades e os possíveis dos tempos da meninice, na qual a novidade é intensa e inventar-se é, apenas, seguir na vida 'criançando', experimentando as possibilidades de infinitas invenções de si geradas a partir do encontro entre adultos e crianças, potencializando dessa forma a infância que habita e rejuvenesce todas as idades.

\section{1 a invenção de si: pistas de como construir-se professor, professora}

"Invento para me conhecer"

(Barros, 2010).

Trabalhar com educação é uma tarefa desafiadora, porque consiste em lidar diretamente com a formação dos aprendizes e, consequentemente, com a formação de si mesmo, isto é, com a formação do educador e educadora.

Partimos do pressuposto de que o processo de aprendizagem e ensino é muito peculiar, e uma das características que torna esse movimento processual uma experiência singular é o fato de a instituição escolar não ser uma fábrica, isto é, não trabalhar com produção de mercadorias feitas em série (apesar, de termos conhecimento de algumas tentativas que visam sujeitar a escola ao mercado). Contudo, a escola lida com seres humanos plenos de histórias, realidades, 
comportamentos, sonhos, desafios e perspectivas únicas, o que torna o ambiente de ensino rico em pluralidade e ímpar em identidades.

Diante desse universo complexo que é a educação escolar, somos provocados a refletir acerca de algumas inquietações: o que é ser professor, professora? Como é ser professor/professora em nosso contexto? Como, na prática, se forma, se inventa, se constrói ou se torna um professor/uma professor/a?

Os caminhos para responder tais interrogações podem ser diversos, como se pode imaginar. No entanto, compreende-se que todas as possíveis respostas serão apenas pistas de como fazê-lo, pois sabemos que não há receita no que se refere à formação, apenas, orientações de como proceder e, ainda assim, sem validade para todas as circunstâncias, em constante mutação.

Ainda nessa perspectiva, convêm indagarmos: é possível nos formarmos no exercício do trabalho? Como fazer do espaço escolar, do espaço de sala de aula, um ambiente de permanente formação? Terão as crianças, os jovens, os adultos e os idosos na relação com seus/suas professores/professoras espaço para lhes ensinarem? E, por fim, terão os professores e as professoras sensibilidade e humildade pedagógica para reconhecerem que podem aprender com seus alunos e alunas?

As indagações e provocações levantadas surgiram após escuta da fala da professora Penha ${ }^{3}$, que disse:

Trabalho com formação, com estudo, mas o lugar que menos tenho estudado, me capacitado, me formado, é no meu local de trabalho, não tenho tido tempo (professora Penha, 2017).

Antes de tudo, é válido esclarecer que não emitimos qualquer juízo de valor em relação à fala da professora Penha, uma vez que seu desabafo tem neste escrito o objetivo de se transformar num convite para que cada educador e educadora reflitam sobre suas próprias relações com o trabalho docente, chamando a atenção sobre suas práticas de ensino, sua compreensão do que venha a ser 'formação',

\footnotetext{
${ }^{3}$ Fala proferida por uma professora da Rede Estadual de Educação do Espírito Santo, na Escola Estadual de Ensino Fundamental e Médio Pio XII, localizada no município de São Mateus, ES, no ano de 2017, durante um Planejamento Coletivo. A identidade da professora foi omitida por questões éticas, por isso foi utilizado um nome fictício.
} 
a infância de ensinar e aprender: inventando com e como criança a arte de ser professor

sobre as condições e qualidade do tempo que dedicam ao exercício da profissão e, ainda, para a maneira como se relacionam com seus alunos, alunas, companheiros e companheiras de trabalho.

Esta reflexão nos parece fundamental e necessária a todo educador e educadora, tendo em vista que lançar a pergunta sobre si é ter a chance de aperfeiçoar o que se faz, pois essa atitude ajuda a reparar equívocos, corrigir desvios e potencializar ações que deram certo, enriquecendo assim a caminhada no universo do aprender e ensinar. Afinal, a educação forma para uma direção ou para outra, deforma, segundo outros, mas, acima de tudo, transforma.

Nessa perspectiva de transformação processual, o filósofo Jacques Rancière (2013), com sua ideia do mestre ignorante enquanto caminho de possibilidade da emancipação intelectual, convoca a cada educador e educadora a superarem, na prática, a condição de mestre explicador, contribuindo para que cada educando seja independente, autônomo, livre de amarras e correntes que possam imobilizar, engessar suas inteligências criadoras.

Encetando, nessa mesma direção, uma necessária superação de práticas que 'despotencializam' as inteligências, o filósofo Walter Kohan apresenta o conceito de professor-pastor como aquele que contribui, assim como o mestre explicador, com o impedimento da emancipação intelectual dos aprendizes e, por isso, também deve ser superado, pois:

[...] ele assume a responsabilidade pelas ações e o destino de sua turma e de cada um dos seus integrantes. Ele se encarrega de cuidar do bem e do mal que possam acontecer dentro da sala de aula. Ele responde por todos os pecados que possam ser cometidos no 'seu' espaço. Embora assuma modalidades leves e participativas, entre o professor e a turma há uma relação de submissão absoluta; sem o professor os alunos não sabem o que fazer, como aprender, de qual maneira comportar-se; eles não saberiam o que está bem e o que está mal, como julgar a atitude de um colega, a falta de esforço de si mesmos para cumprir uma tarefa (Kohan, 2005, p. 87-88, grifo nosso).

Na contramão do que promovem o mestre explicador e o professor-pastor, é que caminha a educação para a invenção de si, pois o objetivo da educação, nesse contexto, é permitir que cada indivíduo possa caminhar por conta própria, desconstruindo a ideia de rebanho, a condição de completa dependência, uma vez 
que, por mais estranho que possa soar, a figura do professor deve 'desaparecer' durante o processo de formação dos aprendizes, deve não mais existir de forma central na caminhada dos educandos. Afinal, os alunos e alunas precisam alçar voos, criarem suas próprias rotas, inventarem seus caminhos e pensamentos. Em síntese, a missão deles e delas é inventar-se, pois:

[...] não há um eu real e escondido a descobrir. Atrás de um véu sempre há outro véu; atrás de uma máscara, outra máscara; atrás de uma pele, outra pele. $\mathrm{O}$ eu que importa é aquele que há sempre além daquele que se toma habitualmente por sujeito: não está por descobrir, mas por inventar; não por realizar, mas por criar da mesma maneira que um artista cria sua obra. Para chegar a ser o que se é, tem que se ser artista de si mesmo (Larrosa, 2009, p. 6465 , grifo nosso).

Os professores devem, sim, durante a caminhada orientar, dar pistas, indicar horizontes, serem como bússolas, e, em seguida, desaparecerem, para que cada aluno e aluna possam voar e desvendarem saberes e caminhos que lhes permitam serem construtores de si, dos seus pensamentos e invenções. Caso contrário, se o aluno, a aluna se mantiver na completa dependência, na sombra de seus mestres, é evidente que a educação não cumpriu seu propósito de transformar os aprendizes em mestres de si. Dito de outro modo, o fazer de cada educador (a) deve se aproximar do que propõe o personagem Zaratustra, inventado pelo filósofo Friedrich Nietzsche:

[...] Zaratustra não deve ser o pastor, nem o cão de um rebanho! Atrair muitos para longe do rebanho - foi para isso que eu vim. O povo e o rebanho devem estar com raiva de mim: de ladrão, é como Zaratustra deve estar sendo chamado pelos pastores (Nietzsche, 2014, p. 33, grifo nosso).

Elencar objetivos e fins pertinentes à educação e à própria arte de educar não é, nesse contexto, a tarefa mais difícil, visto que “[...] a educação visa o homem; na verdade, que sentido terá a educação se ela não estiver voltada para a promoção do homem?"(Saviani, 2013, p. 43). Nesta perspectiva, “[...] como a educação se destina [...] à promoção do homem, percebe-se já a condição básica para alguém ser educador: ser um profundo conhecedor do homem" (Saviani, 2013, p.44). Daí a necessária condição de construir-se, de lançar-se o olhar, a pergunta, a provocação transformadora. 
a infância de ensinar e aprender: inventando com e como criança a arte de ser professor

Todavia, como começarmos? Como fazer esse processo em busca de concretizar as metas propostas? Essas são aqui as questões que se colocam enquanto tarefa sine qua non de uma docência transformadora.

Diante do desafio posto e, tendo em vista a complexidade dos caminhos e rotas possíveis para uma construção autêntica de si e de como inventar-se professor/professora, é que se destacam, a seguir, quatro pontos a serem colocados atenção no percurso:

A) Disposição inicial4: é preciso uma abertura, uma sensibilização, um estar disponível, vulnerável, diante das experiências que nos passam, nos acontecem, nos tocam, nos provocam, pois "[...] a cada dia se passam muitas coisas, porém, ao mesmo tempo, quase nada nos acontece" (Larrosa, 2014, p. 18). Sem essa disponibilidade, essa abertura é improvável acontecer uma viagem transformadora para dentro de si, e, sem isso, é impossível construir-se, inventarse de maneira autêntica e comprometida, pois, para inventar-se professor/professora é necessário experimentar acontecimentos.

O sentido de experiência aqui expresso é tomado emprestado dos pensamentos de Larrosa (2002, p. 24), para quem “[...] a experiência é a passagem da existência, a passagem de um ser que não tem essência ou razão ou fundamento, mas que 'existe' de uma forma sempre singular, finita, imanente, contingente". A experiência é um acontecimento irrepetível, é cada instante que atravessa um indivíduo em seu "existir provisório", e como cada pessoa é um território de passagem singular, a experiência acaba por se tornar um acontecimento intransferível. Nessa perspectiva, Nietzsche (2014, p. 268, grifo nosso) já indicava que "[...] o que quer que faças, ninguém pode fazer por ti", ou seja, cada pessoa é convidada a construir seu próprio trajeto, sentir seu próprio pulsar e, sobretudo, a inventar seu próprio existir.

${ }^{4}$ Pensamento inspirado no subsídio que Kohan (2012), juntamente com seus colaboradores, oferecem na obra: "A escola pública aposta no pensamento", como indicação que pode ajudar na organização e "composição" da experiência de pensamento, sendo a "disposição inicial" o primeiro de seis passos capazes de contribuir para a experiência filosófica acontecer. É importante salientar que o grupo sugere esse passo a passo "[...] não como uma receita, mas como uma matéria plástica para sobre ele começar a compor nossa própria obra" (Kohan, 2012, p. 19). 
B) Experiência de pensamento: segundo Kohan (2009; 2015), é a atitude de pensar e pensar-se de maneira nova, dando novo sentido a cada vivência, a cada acontecimento, a cada movimento da vida, a cada encontro e (des)encontro, possibilitando uma outra (re)organização, uma nova descoberta do pensar sentindo e do sentir pensando. E nesse campo, a filosofia tem contribuições a oferecer, visto que consiste em um saber, uma atitude, que permite gerar questões que guardam sempre algo de inesgotável, isto é, que abre possibilidades, criando visões improváveis, inusitadas, enigmáticas e paradoxais. É a terra onde habita o infinito, um mundo sem fronteiras, a casa do devir; a morada da imaginação; a pura possibilidade de novos inícios. E, como sugere o professor Walter Kohan (2007, p.134): “[...] quem sabe, habitar terras filosóficas diferentes das que estamos acostumados a habitar nos permita ser professores diferentes dos que estamos habituados a ser [...]".

C) Inventar-se no percurso: é o convite para ensinar aprendendo e aprender ensinando, no sentido de Freire (1998, p. 68) "[...] ninguém educa ninguém, ninguém educa a si mesmo, os homens se educam entre si, mediatizados pelo mundo". É fazer-se com o outro em processo de mútua transformação. Nesse sentido, a formação se revela como a capacidade de metamorfosear-se no trajeto, sendo a saída para não ficar se repetindo, aprisionado em uma única versão de si. É o construir-se em movimento ou o exercício de “desaprender oito horas por dia [...]" (Barros, 2016, p. 10), afinal, como já indicava Nietzsche (2014, p. 22, grifo nosso), “o que engrandece o homem é ele ser uma ponte e não um fim; o que se pode amar no homem é ele ser uma transposição e não uma queda. Amo aquele que só sabe viver em extinção".

D) Acriançar-se: é a experiência de fazer-se infantil, de ver o mundo, as coisas que nele estão, e a si mesmo, como algo novo. É aprender com as crianças a ter olhos novos, capazes de espanto diante do mundo, pois "a criança é inocência e esquecimento, um novo começo, um jogo, uma roda que gira por si mesma, um primeiro movimento, um sagrado Sim" (Nietzsche, 2014, p. 39). Olhos velhos, mecânicos, viciados, cansados, não produzem mundos novos, não estreiam pensamentos novos, não percebem a novidade do mundo. Para invenção é preciso 
espanto, assombro, provocação, admiração. E a criança, nesse sentido, apresentase enquanto criação, é aquela que está sendo criada, que está em processo de formação, que "sabe pouco", e por isso mesmo é tão importante e revolucionária, uma vez que carrega a semente do novo, do olhar inédito, do pensamento deslocado, que está inquieto, curioso, desassossegado. Enfim, "criança não é o meio para se chegar ao adulto. Criança é fim, o lugar onde todo adulto deve chegar" (Alves, 2010, p. 37, grifo nosso).

Com base no exposto, percebe-se que o convite é para ser artista de si, para ser revolucionário. Inventar, inventar-se. Esse é o desafio, essa é a questão. A educação, a formação, o ensino, são processos de criação, de transformação do outro e de si mesmo, e a coragem, a necessidade de colocar-se em questão, é central. Para isso, precisamos de olhos novos, de novas perspectivas, de novos começos. Que lugar terá a infância nesse processo de criação? Como podem os infantes colaborarem com a invenção de outros modos de sermos professores/professoras? $\mathrm{O}$ que terão as crianças para ensinar àqueles que ensinam?

\section{2 a infância da novidade: de como espantar-se uma vez mais ${ }^{5}$}

“No presente a mente, o corpo é diferente E o passado é uma roupa que não nos serve mais...

E o que há algum tempo era jovem novo Hoje é antigo, e precisamos todos rejuvenescer"

(Belchior, Velha roupa colorida).

Nascer a cada momento, renovar o mundo a todo instante, reinventar-nos infinitas vezes. A experiência da novidade está expressa no olhar, no ouvir, no narrar, no escrever, no educar, no ser infante. E a grande fonte das novidades se encontra, especialmente, onde há grande concentração da "boa ignorância", ou seja, onde há o reconhecimento de "pouco saber", mas muito desejo de se aproximar do saber. Nessa perspectiva, vale ressaltar que a criança se aproxima do filósofo, ou talvez, seja o filósofo por excelência, uma vez que este não possui o

\footnotetext{
${ }^{5}$ Esta escrita foi inspirada na dissertação de Cunha (2018).
} 
saber, isto é, não é um sábio, mas apenas se relaciona com o saber, está às voltas com o saber. Podemos dizer em síntese que:

[...] a filosofia não é tanto um saber como uma atitude: a da busca, a do cultivo do saber. O filósofo é alguém que sabe manter viva a capacidade de se espantar. [...] o filósofo é aquele que chega e, com toda espécie de perguntas engraçadas, dá uma sacudida e faz ver que nada é óbvio, e que tudo é realmente de pasmar (Iglésias, 2005, p. 17, grifo nosso).

Além das muitas perguntas que são costumeiras no universo infantil, e que tornam os pequenos grandes provocadores do pensar, vale lembrar que eles também são donos de olhos curiosos, que costumam rastejar por entre a imaginação e a invenção. São olhos que têm a capacidade de ver, de "desver", de "transver" o mundo, isto é, de ver de um modo novo, inédito, sempre surpreendente, cheio de graça e frescor. Aliás, podemos dizer que:

A infância é uma vida curiosa, incansável, insatisfeita, mobilizada, vivaz, esperançosa. Uma vida que começa tudo de novo ou que está sempre começando. Uma vida que vê na mudança um sinal de vida e na falta da mudança um sinal de morte (Kohan, 2018, p. 191, grifo nosso).

Como pode ser percebido, o olhar das crianças é muito diferente da maioria do de nós adultos, que quase sempre, só enxergamos "mais do mesmo" e, há muito, não nos espantamos. E o que torna essa tensão preocupante é que, como professores e pais, acabamos, em muitos momentos, tendo grande envergadura para "calar as crianças", suas perguntas, seus espantos, suas curiosidades. Isso ocorre porque, por vezes, nos imaginamos prontos, donos do saber, da verdade e, por isso, capazes de livrarmos “o olhar das crianças" do mundo das ignorâncias, das enganações, do não saber, quando na maioria das vezes estamos moldando-as, enquadrando-as, enformando-as, nos mesmos modelos a que fomos submetidos, ou seja, elas acabam sendo por nós "direcionadas" para serem, apenas, reproduções de cópias, e não versões inéditas, capazes de transformar o mundo. Em síntese: ao invés de inventarmos liberdades, acabamos, nessa perspectiva, "engaiolando" pensamentos. Para ilustrar essa "imagem de pensamento", vejamos:

[...] e aquele colega que tinha ganho um olhar de pássaro era o campeão de aumentar os desacontecimentos. Uma tarde ele falou pra nós que enxergara um lagarto espichado na areia a beber um 
copo de sol. Apareceu um homem que era adepto da razão e disse: lagarto não bebe sol no copo! Isso é uma estultícia. Ele falou de sério. Ficamos instruídos (Barros, 2006, p. 17, grifo nosso).

$\mathrm{Na}$ contramão dessa educação para a "adultização" que, em grande medida, acaba por destruir o caráter criador, inventivo e artístico presente na criança, propomos, aqui, na perspectiva do olhar infantil, aberto, vulnerável, capaz de fazer ver o que normalmente não se vê, uma educação do olhar, da arte do "desver", uma possibilidade educativa que tome como princípio o olhar da criança, da infância, que por vezes nos apresenta uma lógica provocadora e atenta às coisas que nos escapam a observação.

[...] dessa forma de entender a infância, desprende-se, para a educação, uma outra relação com a infância, outra lógica da formação, mais próxima da atenção, do cuidado e escuta da infância, porque se a infância for superada ou apagada, a vida perderia algo que a diminuiria enquanto tal: sem infância, a vida seria menos vida, a qualquer idade. Seguindo essa possibilidade, a educação poderia deixar de se preocupar em formar a meninice em outra coisa que ela não é, para se ocupar de cultivá-la e atendêla para que ela continue sempre viva, sendo o que ela é, em todas as idades (Kohan, 2018, p. 22, grifo nosso).

Como forma de exemplificar a peculiaridade do olhar infantil até aqui mencionado, recorreremos à memória mediante o relato de uma experiência que nos possibilita perceber o mundo por outra ótica/lógica, despertando um sentido novo, um pensamento nascido do espanto.

Essa aventura ocorreu no Centro de Educação Infantil Municipal São João (CEIM São João), localizado na cidade de São Mateus, ES:

Em uma tarde, estava dando aula em uma turma de pré-escola nível I (crianças de 4 anos de idade).

Após as crianças lancharem, na varanda da escola, retornamos para sala de aula. Assim que entrei na sala, a criança $N$ me abordou e, com as duas mãos abertas e juntas sobre a mesa, começou a me interrogar: 
Figura 1 - Mãos da criança $\mathrm{N}$ abertas sobre a mesa.

Criança N: tio Mauro, quantos têm aqui?

Pesquisador: 10 dedos.

Criança $N$ : não, tio, não está certo.

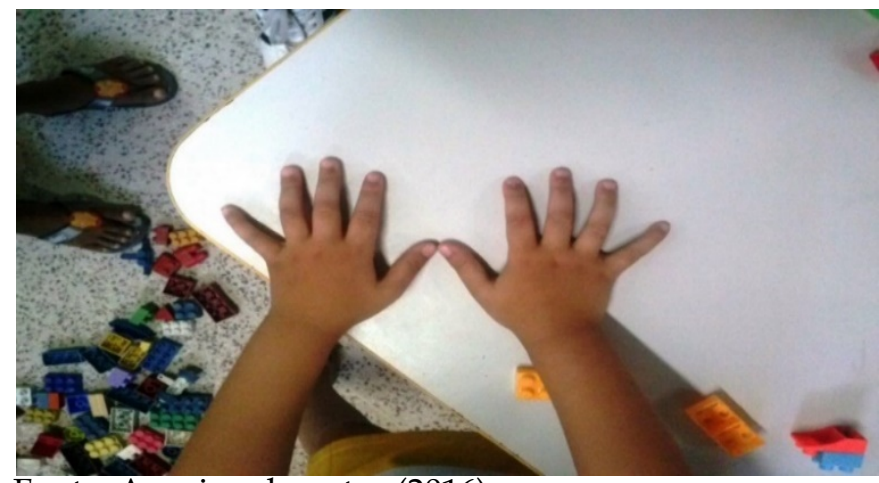

Fonte: Arquivo do autor (2016).

Em seguida, ela mudou a apresentação dos dedos, e mostrou 4 dedos próximos uns dos outros colocando a mão novamente sobre a mesa e me perguntou:

Figura 2 - Criança E tentando imitar a aluna $\mathrm{N}$

Criança N: e, agora, quantos têm aqui?

Pesquisador: 4 dedos.

Criança N: está errado.

Pesquisador: então não sei.

Criança N: são 2 tio. Tio Mauro não sabe nem contar. Tem que contar os "buracos"!

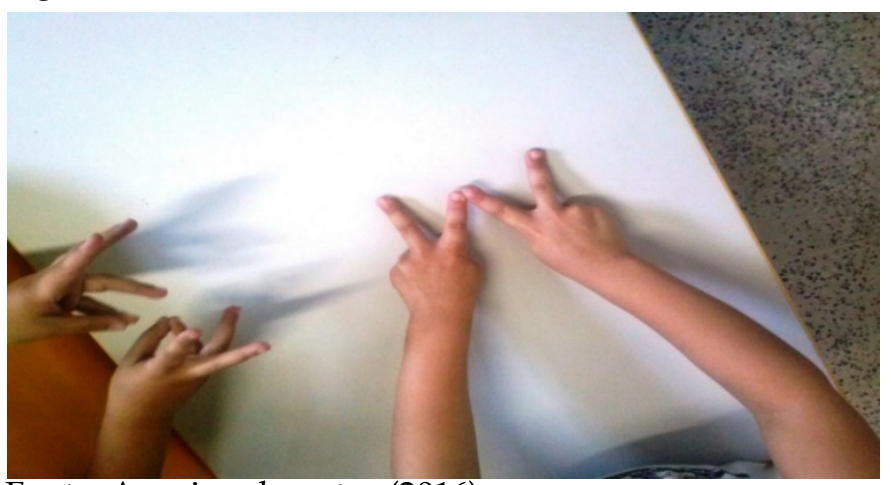

(Relato extraído do caderno de campo do pesquisador Mauro Britto Cunha, 2016)

É possível associar essa experiência a um trecho do poema de Manoel de Barros intitulado: "O menino que carregava água na peneira", pois esse menino da poesia também gostava mais dos "buracos", dos vazios, “[...] a mãe reparou que o menino gostava mais do vazio do que do cheio. Falava que os vazios são maiores e até infinitos" (Barros, 1999, p. 9). Essa imagem de pensamento nos mostra uma meninice que se diverte em não aprisionar, não capturar, não utilizar um recipiente "apropriado" para carregar, transportar a água, mas sua grande brincadeira consiste em deixar a água livre, em apenas movimentá-la, em movimentar-se, em transformar o impossível em possível, em brincar com a imaginação, com os pensamentos, com os vazios. 
Essa experiência ocorrida na escola, associada ao menino do poema, nos deixa intrigados, nos convida a pensamos sobre que espécie de visão seria a das crianças: elas fogem ao previsível, costumam achar sempre mais interessante o que para nós não o é ou, ainda, o que em muitos casos nem sequer vemos. O olhar infantil possui uma intimidade com o espanto, com a novidade, uma observação fascinante, surpreendente. É interessante observar que o pesquisador não via os "buracos", só via os dedos.

Podemos "constatar", com base na experiência narrada, que o pesquisador se acostumou com respostas fáceis, com caminhos e estratégias de pensamentos sempre iguais. Caiu numa rotina, numa visão mecânica de ver e conceber o mundo, as coisas, sempre de um mesmo modo, ficou com olhos empobrecidos, engaiolados, engessados, ficou parcialmente "cego".

Interrogamos agora: será que assim como na história narrada ainda e também percebemos, vemos o outro e a nós mesmo por uma lógica mecanizada? Quantas vezes vimos e vemos algo ou alguém, mas não visualizamos seus detalhes? Quantos pensamentos, afetos, sentimentos, palavras, encontros e (des)encontros ocorreram sem que percebêssemos que nossos olhos estavam/estão "viciados"? Será que vemos superficialmente e desprezamos os fragmentos minúsculos dos acontecimentos? Será que, ao invés de nos abrirmos para as experiências, temos fugido delas? Como mantermos a força da curiosidade infantil que nos habita independente de qual seja nossa idade? E ainda: como mantermos e potencializarmos o olhar atento, provocador, intenso e surpreendente das crianças?

Nesse movimento de construir-se professor/professora, somos convidados pela provocação da infância a inventarmos olhos que pensam sentindo, que brinquem com o mundo, que sejam pacientes, desapressados, interessados, que sejam íntimos da imaginação, uma vez que "[...] o olho vê, a lembrança revê, e a imaginação transvê. É preciso transver o mundo" (Barros, 2000, p. 75, grifo nosso).

Compreendemos que o olhar infantil é a pura possibilidade de criação, é um campo aberto, sem estrada, sem placa, só um vasto horizonte, fonte das ideias 
a ser inventadas, o lugar onde os pensamentos inéditos brincam e se inauguram. Estaria aí uma possibilidade para inventar-se professor? Começar pelo resgate do olhar da infância, tornar-se mais curioso, aberto, criativo, isto é, começar pela educação do próprio olhar, aprender com as crianças a preciosa arte do "desver", do "transver"? Afinal, como já lembrava o cantor Belchior, "precisamos todos rejuvenescer"...

\title{
3 tempos infantis: um convite a construir-se nas experiências dos encontros
}

\author{
“Há um menino \\ Há um moleque \\ Morando sempre no meu coração \\ Toda vez que o adulto fraqueja \\ Ele vem pra me dar a mão"
}

(Milton Nascimento, Bola de Meia, Bola de Gude)

A canção de Milton Nascimento apresenta uma concepção de meninice que habita um tempo não cronológico, uma infância que se movimenta por toda a vida, escapando à demarcação de uma temporalidade específica, uma época, um ano, uma tarde, uma hora... Ao contrário, esse tempo não cronológico da meninice se movimenta como uma dança movediça, um tempo próprio do devir, um sempre por fazer-se. O menino/moleque tem a ver com aspectos de intensidade, e não com faixa etária, cronologia ou linearidade. Observa-se aqui uma potente conexão entre a música e o pensamento intrigante e enigmático de Heráclito descrito no fragmento 52, ao afirmar que “[...] o tempo é uma criança que brinca; o reino de uma criança[...]" (Kohan, 2013, p. 17, grifo nosso).

A partir disso, compreende-se que o conceito de infância rompe com a ideia da temporalidade matemática (chrónos), pois a infância habita o tempo aiónico, é a condição de seguir na vida "criançando". Pode-se dizer, em síntese, conforme Kohan (2007, p. 86), que “[...] se uma lógica temporal segue os números, outra brinca com os números". 
Ao pensarmos a infância segundo a lógica do chrónos limitamos sua condição a criança, isto é, a uma faixa etária, mas se rompemos essa forma de pensamento e estabelecemos ligação com aión, possibilitamos uma condição potente da infância, uma infância que pode ser vivida a qualquer tempo, época, que se movimenta, que está na criança, mas não somente nela, e sim em todo lugar que a vivência da novidade se instala. Pode ser a vivência da infância da paixão, a infância da língua, a infância da velhice. Aqui, por exemplo: lançamos o desafio de vivenciarmos a infância de nos construir professores/professoras a partir do olhar das crianças.

[...] ah, a infância! Tudo começa a mudar quando se chega aí. [...] Experiência da imanência, a infância não pressupõe um progresso ou uma evolução para ser acessada, mas antes uma 'involução criadora' que nos coloca em contato com o élan da vida, isto é, com o movimento pelo qual nos diferenciamos de nós mesmos (Melo, 2012, p. 246, grifo nosso).

Essa infância vista pela ótica de uma temporalidade movediça apresenta outras formas de ser criança que escapam ao tempo cronológico, restrito, controlado por fases, períodos, faixa etária. Por isso, o menino/moleque que habita cada coração pode estender as mãos toda vez que se fraqueja porque ele brinca com o tempo, visto que "no reino infantil, que é o tempo, não há sucessão nem consecutividade, mas intensidade da duração" (Kohan, 2007, p. 86). Pode-se dizer, sobretudo, que esse menino/moleque remete ao devir-criança, pois:

[...] a criança supre o histórico pela aliança do presente com o eterno. Seu tempo não é linear, nem evolutivo, nem genético, nem dialético, mas está cheio de clarões, de intermitências. A criança é um presente fora do presente, isto é, um presente inatual intempestivo (Larrosa, 2009, p. 103, grifo nosso).

Em síntese: a infância não é uma etapa, é uma condição da vida, visto que "[...] a infância atravessa a vida toda como uma força que lhe outorga curiosidade, alegria, vitalidade" (Kohan, 2019, p.161, grifo nosso). Porém, pensamos que, quando um indivíduo está profundamente mergulhado no tempo cronológico, nos tempos que correm, essa condição fica, em certa medida, esquecida, adormecida, negada, silenciada, colocada à margem, fora de questão.

O que propomos aqui é uma aproximação entre crianças e adultos, imaginando que talvez seja essa relação um movimento rico de encontro, 
(re)encontro, (des)encontro, de amizade, de alegria, que possa fertilizar, potencializar, impulsionar, gerar condições que possibilitem tornar mais evidente e ativa essa condição de ser infante em qualquer idade. Sendo essa aventura uma forma potente de cultivar pensamentos, capaz de contribuir com o inventar-se, o construir-se e, também, uma oportunidade para criação e experiência de fazer-se professor e professora aprendendo com as crianças, afinal, como indica Kohan (2019, p. 161, grifo nosso), “[...] a infância não é algo a ser educado, mas algo que educa".

Essa relação, esse encontro é um convite para fazer-se educador/educadora participando de uma grande brincadeira com o tempo, com as crianças, movendose com paciência, com passos delicados, desapressados, colocando atenção no olhar, no sentir, no pensar... Adotando diante do tempo que corre outra forma de ser e estar no mundo, no sentido de não entrarmos no jogo da correria, da pressa, de não seguirmos as regras dos "tempos modernos", pois, entende-se que o movimento acelerado pode cegar, mecanizar, tirar a condição de experimentar o pensamento com maior intensidade, riqueza e importância, e isso, sem dúvida, seria um dano irreparável porque o fluxo da vida não nos permite reviver duas vezes um mesmo instante, e perder a preciosidade de um momento é o que se deseja evitar.

É importante nesse contexto colocarmos especial atenção na forma como se experimenta, se explora, se desenvolve a relação, a aproximação com os educandos, pois, segundo Larrosa (2009) a invenção de si passa pelo modo como se experimenta o mundo, o tempo, os acontecimentos, os encontros... Está intimamente relacionado ao modo como cada pessoa se coloca em jogo, como cada um se prova, se ensaia, se relaciona com a própria destruição e (re)construção de si mesmo, num movimento incessante. Isto é, cada encontro entre professores e alunos devem ser vividos de maneira aberta, exposta, intensa, aproveitando a riqueza do diálogo, do afeto, do pensamento renovador como elementos-chave na construção de si, na experimentação das inúmeras formas de ser professor/professora, seguindo nesta esteira onde o aprendizado sempre está por vir, sempre está por ser feito. 
Compreendemos que ao "experienciar" a infância do/no tempo, sentimos o desejo de seguir na vida "criançando", brincando com o tempo, com os pensamentos, com as possibilidades de infinitas invenções de si. Abre-se no encontro entre adultos e crianças, entre professores e alunos, entre indivíduos interessados em dialogar e aproximar-se do saber, um anseio em potencializar a infância que habita cada pessoa, com vista em experimentar o mundo com maior intensidade, a si mesmo com maior alegria e cada encontro com a vivacidade irrepetível de uma forma sempre provisória de ser e estar. Esta será sempre uma brincadeira sem fim, um exercício de busca permanente, sendo esse fluxo, ao fim e ao cabo,o que transforma aqueles que se põem em movimento nesta dinâmica de pensar, pensar-se, inventar-se, fazer-se, inaugurar-se, transformar-se, buscar-se, criar-se...

\section{considerações finais}

O presente escrito não objetiva encerrar, menos ainda ser uma resposta às provocações suscitadas até aqui. Ao contrário, se propõe com e a partir das reflexões feitas, provocadas, 'desencadear', isto é, abrir os 'cadeados' que aprisionam ou tentam aprisionar a grandeza do pensar sentindo e do sentir pensando.

Provocamos apenas um primeiro passo, num movimento de experiência que pretende aproximar adultos e crianças, mediados pela amizade ao saber. Compreendendo esse encontro enquanto caminho de possibilidade, fértil o bastante para potencializar a infância que habita todas as idades, pois, como sugere Zaratustra “[...] Aquele que quer aprender a voar um dia, deve primeiro, ficar de pé, andar, correr, escalar e dançar - não se pode aprender a voar voando!" (Nietzsche, 2014, p. 262).

O convite é para que cada pessoa coloque atenção no olhar, no caminhar, nos encontros, na construção de si, nessa grande brincadeira que é a invenção de se construir educador, educadora. Aprendendo com as crianças a experimentar o pensamento de outras formas, como um brinquedo, como algo a ser explorado, cultivado, fecundado... 
Apostamos na ideia de que as crianças podem nos ajudar a descobrir outras formas de relação com as ideias, com os afetos, com os sentidos, com as emoções, (re)organizando ou (des)organizando cada pensamento, permitindo a cada um imaginar, experimentar, construir outros mundo, outras formas de ser e estar no fluxo da vida.

É importante destacarmos que a escola ocupa importante papel nessa dinâmica de encontro, de invenção de si, pois ela deve ser o lugar do diálogo por excelência. Deve ser lugar de voz, de fala, de escuta, de encontro e aprendizado entre adultos e crianças.

Professores não devem calar seus alunos, tirar-lhes a voz. Ao contrário, devem ser propagadores do direito de fala, do direito ao debate, à provocação, à criação, à invenção. Devem dar voz à infância que habita cada pessoa. Afinal, por que proibir as perguntas? Para que calar as vozes? Por que marginalizar a infância criadora que nos acompanha e nos potencializa?

Somos chamados à invenção de outras formas de ver, de "desver", de "transver". De fazer-se às avessas, como nos provoca o poema "Diário de Bugrinho (excertos)" de Manoel de Barros (2000, p. 30), quando destaca que o neto viu o avô lendo e disse: “[...] vô! O livro está de cabeça pra baixo. Estou deslendo". Essa é uma imagem que provoca o pensamento, que desloca as certezas, as lógicas da razão. É um convite a experimentar o mundo de outras maneiras, de formas inimaginadas, impensadas.

A infância nos convida, sobretudo, a embarcarmos num voo sobre espaços desconhecidos; a viajarmos ao universo do não saber; a mergulharmos no desejo da descoberta; numa viagem sem bússola, sem mapas, sem pistas, sem coordenadas, uma aventura feita apenas de exposição e curiosidade. Nos chama a dar um profundo mergulho nas diferentes formas de ser e estar no mundo, assim como Barros (2000) ao dizer: que em menino sonhava em ter uma perna mais curta, só para poder andar torto.

Com base no exposto, compreendemos que mergulhar no universo da infância é apostar na criação do espírito aventureiro, é avançar às cegas em um mundo ainda por ser inventado, é exercitar a condição de exposição, é deixar que 
a infância de ensinar e aprender: inventando com e como criança a arte de ser professor

algo aconteça, que possibilite mover-se em busca de pensamentos mais surpreendentes, potentes, inesgotáveis, inéditos...Entre adultos e crianças, professores e alunos é possível inventar um mundo novo a cada dia, maneiras múltiplas de ver, de pensar, de viver a infância do pensamento e o pensamento da infância, percebendo que juntos se constroem possibilidades outras de ser, de sentir, de cultivar ideias, de transformar e transformar-se.

Queremos nesse precioso desafio que é o de inventar-se professor, professora trazermos outras questões, outras perspectivas que nos provocam, nos inquietam a fim de não fecharmos o diálogo, mas provocá-lo. Seguem: é possível inventarmos outras formas de experimentar a filosofia e a infância nestes tempos de pandemia? O que impede o nosso pensamento de viver sua infância de maneira plena? O que potencializa o pensamento da infância existente em cada um de nós? Que escolas queremos, podemos e desejamos construir juntos? Que professores estamos nós inventando? Como mantermos os pensamentos quentes, desengaiolados, desassossegado nestes tempos de isolamento social?

\section{referências}

Alves, Rubem. Conversas sobre educação. 10. ed. São Paulo: Verus Editora, 2010.

Barros, Manoel de. Exercícios de ser criança. Rio de Janeiro: Salamandra, 1999.

Barros, Manoel de. Livro sobre nada. 8. ed. Rio de Janeiro: Record, 2000.

Barros, Manoel de. Poemas rupestres. Ilustração de Martha Barros. 2. ed. Rio de Janeiro: Best Seller, 2006.

Barros, Manoel de. Menino do mato. São Paulo: Leya, 2010.

Barros, Manoel de O livro das ignorãças. Rio de Janeiro: Alfaguara, 2016.

Cunha, Mauro Britto. Em busca da infância: experiências filosóficas com crianças numa escola pública municipal de São Mateus, ES. 2018. 180 f. Dissertação (Mestrado em Ensino na Educação Básica) - Universidade Federal do Espírito Santo, São Mateus/ES.

Freire, Paulo. Pedagogia do Oprimido. 25. ed. Rio de Janeiro: Paz e Terra, 1998.

Gallo, Sílvio. Metodologia do ensino de filosofia: uma didática para o ensino médio. São Paulo: Papirus, 2012.

Kohan, Walter Omar. Infância: entre educação e filosofia. 1. ed. (Coleção “Educação: Experiência \& Sentido). Belo Horizonte: Autêntica, 2005.

Kohan, Walter Omar. Infância, estrangeiridade e ignorância: ensaios de filosofia e educação. (Coleção "Educação: Experiência \& Sentido). Belo horizonte: Autêntica, 2007.

Kohan, Walter Omar. Filosofia: o paradoxo de aprender e ensinar. (Coleção “Ensino de filosofia”). Belo Horizonte: Autêntica, 2009. 
Kohan, Walter Omar. Palavras, passos e nomes para um projeto. In: Kohan, Walter Omar; Olarieta, Beatriz Fabiana (Orgs). A escola pública aposta no pensamento. (Coleção “Ensino de filosofia"). Belo Horizonte: Autêntica, 2012.

Kohan, Walter Omar. Pensar com Heráclito. (Org. e Trad.) Rio de Janeiro: Lamparina, 2013.

Kohan, Walter Omar. O mestre inventor: relatos de um viajante educador. 1. ed. Tradução Hélia Freitas. (Coleção "Educação: Experiência e Sentido"). Belo Horizonte: Autêntica, 2015.

Kohan, Walter Omar. Paulo Freire: outras infâncias para a infância. Educação em Revista, v. 34. Belo Horizonte, 2018.

Kohan, Walter Omar. Paulo Freire, mais do que nunca: uma bibliografia filosófica. Belo Horizonte: Vestígio, 2019.

Larrosa, Jorge. Notas sobre a experiência e o saber de experiência. Revista Brasileira de Educação, Rio de Janeiro, n. 19, p. 20-28, jan-abr. 2002. Disponível em:<https://www.redalyc.org/articulo.oa?id=27501903>. Acesso em: 11 julho. 2020.

Larrosa, Jorge. Nietzsche E a Educação. Traduzido por Semíramis Gorini da Veiga. 3. ed. (Coleção "Pensadores \& Educação). Belo Horizonte: Autêntica Editora, 2009.

Larrosa, Jorge. Tremores: escritos sobre experiência. Tradução Cristina Antunes; João Wanderley Geraldi. 1. ed. (Coleção “Educação: Experiência \& Sentido). Belo Horizonte: Autêntica, 2014.

Iglésias, Maura. O que é filosofia e para que serve. In: Rezende, Antonio (Org). Curso de filosofia: para professores e alunos dos cursos de segundo grau e de graduação. 13. ed. Rio de Janeiro: Jorge Zahar, 2005.

Melo, Danilo Augusto Santos. Palavras, passos e nomes para um projeto. In: Kohan, Walter Omar; Olarieta, Beatriz Fabiana (Orgs). A escola pública aposta no pensamento. (Coleção "Ensino de filosofia"). Belo Horizonte: Autêntica, 2012.

Nietzsche, Friedrich. Assim falou Zaratustra: um livro para todos e para ninguém. Tradução Carlos Duarte e Anna Duarte. São Paulo: Martin Claret, 2014.

Rancière, Jacques. O mestre ignorante: cinco lições sobre a emancipação intelectual. Tradução de Lílian do Valle. 3. ed. Belo Horizonte: Autêntica, 2013.

Saviani, Dermeval. Educação: do senso comum à consciência filosófica. 19. ed. São Paulo: Autores Associados, 2013.

recebido em: 12.06 .2020

aprovado em: 29.07 .2020 